\title{
LA DISOLUCIÓN DE LAS IDENTIDADES. ESPACIO PÚBLICO Y DERECHO A LA INDIFERENCIA
}

\author{
Manuel Delgado \\ Antropólogo, Universitat de Barcelona y miembro del ERAPI
}

El espacio público es un escenario en el que la convivencia entre extraños, quien sabe si potencialmente incompatible en otros planos de la vida social, se demuestra viable a partir de una serie de mínimos competenciales consensuados, con frecuencia sobre la marcha. Las puestas en común no están basadas aquí en una comunión, sino en la comunicación. Lo que se articula no son autenticidades identitarias, sino roles en los que la impostura y la mentira no están nunca del todo descartadas. Entran en juego entonces no las verdades personales de cada cual, sino exterioridades, apariencias que dan a escoger entre una interacción focalizada o una interacción basada en la indiferencia. No es una intersubjetividad, como se pretendeía desde perspectivas fenomenológicas, sino una pura interobjetividad, el pacto abierto que firman personas que quieren ser tomadas no por lo que son o creen ser, sino tan sólo por lo que parecen o pretenden parecer. Reducido a una organicidad minima, este escenario es cualquier cosa menos el de una comunidad territorializable.

\section{El espacio público como esfera de integración}

Deberíamos preguntarnos, de entrada, hasta qué punto se está haciendo lo preciso en la pedagogía de los valores civiles, sobre todo por lo que hace a prevenir actitudes socales excluyentes hacia aquellos que han sido presentados previamente como culturalmente «diferentes», una forma con frecuencia eufemística de decir «problemáticos». No sería un error sospechar que, en muchos sentidos, los discursos hoy por hoy hegemónicos en torno a conceptos como multiculturalidad o interculturalidad, así como una no menos confusa defensa del derecho a la diferencia, no están contribuyendo a hacer aumentar los niveles de predisposición a la convivencia con los que no son como la mayoría, sino que bien podrían ser entendidos como sutilmente al servicio de ideologías y prácticas estigmatizadoras. Más radicalmente todavía, se podría afirmar -ya hay quien lo ha hecho- ${ }^{1}$ que el multiculturalismo y el interculturalismo que se han incorporado a la creciente trivialización del antirracismo -a nivel escolar, a nivel mediático, a nivel civil en general- son, hoy por hoy, las ideologías racistas por antonomasia, aquellas que más están haciendo para sustituir el viejo y desacreditado racismo biológico por otro 
basado en el determinismo cultural, mucho más eficaz que el primero de cara a mostrar como naturales e irrevocables las diferencias humanas.

Estas nuevas lógicas prácticas e ideológicas para la exclusión social, basadas en la retórica del diferencialismo, deberían encontrar un antídoto en el elogio del espacio público entendido en su doble acepción, como ámbito físico concreto y como concepto político abstracto. En el primer caso -apoteosis de la posibilidad de juntar del espacio kantiano-, se entiende que el espacio público es un escenario potencialmente inagotable para la comunicación y el intercambio, definido por su accesibilidad $y$ en que hablar de un otro es un pleonasmo, puesto que allí no hay otra cosa que otros, principio del que el propio sujeto -permanentemente autoextrañado, puesto que procura conteplarse en todo momento tal y como los demás le están contemplando- no constituye ninguna excepción. Es, pues, un espacio de la diferenciación generalizada, en que se producen constantes negociaciones en que los copresentes juegan con los diferentes grados de la aproximación y el distanciamiento. Las figuras intercambiables del espectador y del actor usan un escenario del que todos pueden apropiarse, pero que nadie puede reclamar como propiedad. Como categoría teórica, el espacio público es el lugar de lo compartido por excelencia, marco de lo político como campo de encuentro transpersonal y región sometida a leyes que deberían ser garantía para la igualdad. Lugar para la mediación entre sociedad y Estado -lo que equivale a decir entre sociabilidad y ciudada- nía-, el espacio público está concebido para que en él puedan cobrar vida los principios democráticos que hacen posible el libre flujo de iniciativas, juicios e ideas. El espacio público es, en cualquier caso y como todo, una construcción social, pero una construcción social no finalizada, inconclusa, puesto que es, por definición, una máquina permanentemente activada de producción de nuevos significados y de lucha contra la tendencia que cualquier discurso pueda experimentar hacia la fijación. El espacio público es lo que se halla en las antípodas de lo cristalizado, de lo fijo, puesto que es el ámbito de las ocupaciones efímeras y de las circulaciones.

Este elogio democrático del espacio público, como instrumento para una pedagogía de la ciudadanía y el civismo, pretende contrarrestar la polémica abierta por los teóricos del «reconocimiento», en favor de una mayor consideración de los rasgos singulares de los que se supone que depende la integridad moral de los miembros de ciertas comunidades. Los argumentos que siguen advierten de que, porque es del todo incompatible con esos valores de los que el espacio público es portador, esa manera de enfocar la heterogeneidad en las sociedades contemporáneas es, por principio, perversa y distorsionadora. Lo es en la medida en que -a años luz de la actividad calidoscópica de los espacios públicos- imagina la sociedad en que vivimos dividida en compartimentos comunitarios exentos y cerrados, organizados a partir de estructuras cognitivas y costumbrarias propias más bien impermeables. Dentro de cada uno de estos supuestos cubículos culturales cada persona 
viviría inmersa en un universo de significaciones del que, por definición -y siguiendo todos los tópicos asociados a la imaginaria autonomía de los fenómenos culturales-, no querría ni al fin y al cabo podría escapar. Este discurso enfatiza sobre todo la necesidad de que las instancias sociales en que se han de registrar unos máximos niveles de integración no pierdan nunca de vista quiénes son aquellos a los que pretende incorporar, es decir, cuál es y en qué consiste su identidad. La premisa de este postulado -revitalización del viejo énfasis romántico y antiilustrado en los particularismos- es que esta identidad de matriz etnicocultural traduce características definitorias fundamentales para cada ser humano y que su función estructuradora de la personalidad exige su reconocimiento por parte de los otros, pero también por parte de las instituciones sociales y políticas.

\section{De la diferencia a la desigualdad}

Frente a esta pedagogía de la «diversidad cultural», que presume de entrada que sólo algunos de entre nosotros son diversos y el resto no, y que la sociedad está dividida en cuadrículas culturales claramente definidas que han de ser reconocidas y aceptadas, la alternativa, por lo que hace a una educación en valores, reclamaría un cierto retorno a los viejos principios republicanos de la civilidad, que, por principio, es ajeno a cualquier reconocimiento de aquellos a quienes se aplica más allá o antes de su identidad básica como personas. En otros términos, cualquier diferenciación en el trato que han de merecer los individuos a partir de una cosa tan poco obje- tivable como es la adhesión cultural es, por principio, incompatible con los principios del igualitarismo democrático. Tal axioma fue ya postulado por Rousseau, cuando en su Discurso sobre el origen de la desigualdad advierte que es cuando la gente reclama y obtiene una consideración preferencial del tipo que sea, una estima particular por parte del Estado o de la sociedad en su conjunto, que aparecen la injusticia y la tiranía. El reconocimiento es, para Rousseau, el paso previo a la desigualdad ${ }^{2}$. Frente al reconocimiento de las diferencias, los principios democráticos igualitaristas -que los relativistas radicales han tildado como "particularismo etnocéntrico teñido de universalidad»-, todo y ser cierto que son un producto específicamente europeo, son el único instrumento que nos puede servir para organizar una sociedad cada vez más mundializada, pero fundamentalmente cada vez más heterogénea, compleja, paradójica y contradictoria.

Esta apuesta a favor de los valores constituyentes de la modernidad no cuestiona en absoluto que las personas tienen identidad propia y que esta identidad recibe su sentido frecuentemente incluyéndose en contextos asociativos específicos, como pueden ser una familia, una confesión religiosa, una partido político o una comunidad de personas procedentes de un mismo país, colectividades todas ellas culturales sin duda. Tampoco discute que en la vida pública los individuos esperan recibir un trato que tenga en cuenta sus particularidades, ya sean psicológicas, familiares, sociales, culturales, etc. Lo que se rebate es el presupuesto según el cual sólo algunas perso- 
nas han de recibir este tratamiento que focaliza sus diferencias, puesto que todos los concurrentes en las actividades en púbico podrían reclamar con razón que las suyas son condiciones vitales igualmente únicas e irrepetibles. Esta consideración especial, que «reconoce» sólo algunos «diferentes», coloca de hecho a su presunto beneficiario en una especie de estado de excepción y sirve por señalar su presencia como una anomalía que ha de ser explicada públicamente y neutralizada por medio de una relación singular. Una particularidad cultural concreta como, pongamos por caso, el idioma, que podría ser inicialmente problemática pero que puede quedar solventada con un soporte adecuado, acaba impregnando la totalidad de la persona que la presenta, que pasa a ser toda ella incluida dentro de una catalogación - «inmigrante», «minoría cultural», «minoría étnica»- que lo define de una forma absoluta, a la manera que como vemos que pasa con aquellos que presentando una deficiencia o una minusvalidez parcial, acaba convirtiéndose en deficientes o minusválidos integrales.

Como alternativa a la perspectiva diferencialista, una educación en los valores de la ciudadanía haría suyos los viejos principios del republicanismo político, según el cual no es pertinente una consideración sustantiva de las diferencias humanas, definidas todas ellas a partir de una condición absolutamente contingente y procesual. El elogio del espacio público presume que todas las personas que en él concurren son diferentes pero -dejando de lado aquellos rasgos que puedan implicar una desventaja objetiva y los efectos de los cuales deban ser aliviados por los correspondientes mecanismos sociales de regulación y equilibrio- su diferencia debería resultarle indiferente a una sociedad y a un Estado que si se autoasumen como democráticos es, por principio, porque son neutrales, laicos, no sólo en el plano confesional, sino también en el cultural, y que, por tanto, no tienen nada que decir sobre el sentido último de la existencia humana ni sobre otros valores generales que no fueran aquellos de los cuales depende el bienestar y la convivencia del conjunto de sus miembros o administrados.

No es que se entienda que la sociedad es uniforme, sino precisamente todo lo contrario: lo que se constata es que la vida social es demasiado plural y complicada para someterla a una única cosmovisión. La convivencia, se entiende, sólo es viable limitando los efectos disolventes de una heterogeneidad que aumenta constantemente y que no puede ni ha de ser totalmente vencida, puesto que de ella depende la prosperidad e incluso la supervivencia misma de esta sociedad. Con esta finalidad, unos mínimos de consenso garantizan que la copresencia entre distintos y hasta entre incompatibles será posible y podrá brindar sus efectos benéficos en forma de todo tipo de simbiosis. En este contexto, cada cual -por descontado- tiene derecho a concebir el universo como crea pertinente, en función de sus propias convicciones o de la visión que se desprenda del grupo humano de que se siente parte, pero sus opciones culturales constituyen un asunto estrictamente privado que sólo ha de ser tenido en consideración si eventualmente llega a afectar aquellos dominios en 
que se realiza la vida colectiva y, ni que decir tiene, si vulnera una ley democrática. Ese es el sentido, en última instancia, de la idea misma de espacio público, cuyos valores de regulación y mediación entre instancias sociales y políticas se rige por reglas que no son las que ordenan la vida personal y privada de cada cual, sino otras de un orden superior. En resumen, esta perspectiva no tiene presente nunca quién es cada persona, sino únicamente qué hace o, especialmente, qué le pasa.

De acuerdo con odo lo expuesto hasta aquí, se producen dos instancias de integración de la persona: la pública y la privada. Los conceptos de público/privado se organizan a partir de diferentes criterios que se entrecruzan, unos relativos a actividades, otros a espacios. Uno de ellos remite al derecho que los individuos pueden reclamar de no verse afectados por una intervención exterior, que en este campo sería considerada ilegítima. Una actividad corresponde a la esfera privada cuando puede mantenerse a salvo de cualquier injerencia de no importa qué instancia exterior y resulta ajena o indiferente a las actividades públicas, por ejemplo de tipo profesional. Lo privado también puede aludir a actividades no sometidas a móvil social, puesto que se entiende que no implican ninguna forma de interés colectivo, es decir no tienen consecuencias para los demás. Se trata, pues, de actividades sin impacto global, lo que no quiere decir que carezcan de importancia para el individuo. También es público aquello que resulta accesible incondicionalmente o según condiciones idénticas para todos -un cine, un transporte público-. Lo privado, al contrario, suscita una selección que determina la posibilidad de acceso a partir de razones siempre específicas.

La no accesibilidad de lo privado conlleva casi automáticamente la no-visibilidad social. Es privado lo que no se desea dar a conocer, lo que no se muestra, lo que no desvela, lo que se resguarda de la atención de los demás, lo que no se expresa. Si los espacios públicos exigen la obediencia o un conjunto de pautas preestablecidas e iguales para todos, en los espacios privados uno puede actuar a su manera, puede «dejarse llevar»y abandonarse a conductas que serían consideradas impropias o inadecuadas en contextos de publicidad.

Lo privado se asocia también a lo «personal», lo que no tiene influencia directa sobre las personas con las que se va entrando en contacto, lo que no importa o no debería importarles a los demás. También a lo propio, en el sentido de lo que es propiedad particular, lo que los demás no pueden usar si o es con autorización. Lo público no es una mera extensión de lo privado. Antes bien, podría entenderse que es su contrario. Ello no niega que la relación entre público y privado es por definición conflictiva, paradójica y contradictoria. Fuera de los casos en que las leyes se arrogan la potestad de separar un ámbito del otro, la inmensa mayoría de veces el vínculo entre lo público y lo privado no supone tanto una relación incierta entre dos esferas supuestamente definibles con claridad, sino una relación entre dos ámbitos ya de por sí oscilantes e indeterminados, dos modos afirmativos que buscan su estabilidad sin dar jamás con ella, 
pero el establecimiento de cuya línea de distinción puede ser, en última instancia, reclamado por el individuo como un derecho.

Tenemos entonces que existen esos dos campos de integración. Uno privado o incluso intimo, en que el individuo asume -se presume que voluntariamente- unos determinados sistemas de mundo sustantivos. El otro, público, marcado en principio por el libre acuerdo a la hora de poner entre paréntesis los sentimientos, ideas y motivaciones singulares en nombre de la conformación ética de una sociedad civil y de una sociedad política igualitaria, de las cuales el protagonismo absoluto recae en un ser sin atributo, masa corpórea inidentificada, perfil indeterminado al que la simple presencia física otorga derechos y obligaciones, personaje anónimo que bajo explicaciones sobre sus adhesiones morales particulares. Esta figura que encarna los principios de igualdad y universalidad democrática no es otra que la del ciudadano, la concreción práctica del cual es la del personaje usuario, depositario de derechos sociales asociados a la ciudadanía democrática y lugar en que se hace o debería hacerse posible el equilibrio entre un orden social desigual e injusto y un orden político que se supone equitativo. El usuario se constituye así en depositario y ejecutor de derechos que se arraigan en la concepción misma de civilidad democrática, en la medida en que es en él quien, como si fuese naturalmente, recibe los beneficios de un mínimo de simetría ante los avatares y las inclemencias de la vida y la garantía de que tendrá acceso a las prestaciones sociales y

culturales necesarias para un elemental desarrollo como persona.

La defensa de los ideales modernos que orientan una esfera pública en la que los concurrrentes disfrutan de un trato igual, simétrico y solidario no pasa, como alternativa al discurso multicultural al uso, por una exaltación de los principios liberales como la que han formulado Rawls y otros autores. Ha sido Jügen Habermas quien mejor ha formulado esta opción que él mismo define como republicanismo kantiano ${ }^{3}$. Su referente sería un retorno a Kant y al problema filosófico que planteara a propósito de la regulación armónica de una convivencia entre diferentes en una sociedad que ha renunciado a la unanimidad cosmovisional. La libre circulación y competencia de los sentidos de la vida coloca a la sociedad y al Estado modernos, en efecto, ante una situación en la que el conflicto deviene norma, por no decir requisito, para una madeja de interacciones cada vez más densa, a cargo de individuos y corporaciones sumergidos en dinámicas de diferenciación y especialización. Tanto la organización social como el Estado mismo han de disponer de instrumentos normativos que limiten y regulen el ejercicio de las diferencias y faciliten la cooperación entre segmentos sociales no pocas veces incompatibles, pero, a pesar de ello - $\mathrm{e}$ incluso a veces a causa de ello-, indispensables los unos para los otros. Entre estos instrumentos ocupa un lugar estratégico -insistamos- la categoría abstracta de ciudadano, el escenario natural del cual es un ámbito público siempre vacante y disponible para la acción social, no definido institucionalmente y que considera del todo 
irrelevante la «auténtica» identidad de quienes allí interactúan.

En este espacio público que la modernidad inaugura como el lugar de la epifanía de los valores democráticos las expresiones de pluralidad se dan por descontadas. El igualitarismo democrático no niega que existen singularidades; antes al contrario: se adapta normativamente a un universo en que las particularidades proliferan infinitamente, en que las composiciones comunitarias mutan constantemente y no tienen fronteras estables y en las que ni tan sólo el individuo puede ser reducido a su propia unidad, puesto que también él es una multiplicidad inorgánica e incongruente de rasgos. Lo que se proclama desde el igualitarismo es que las diferencias existentes, incalculables ya, son irrelevantes. La diferenciación generalizada es un hecho y basta, e incluso lo que pueda tener de conflictivo su despliegue se considera un fenómeno casi natural y no por fuerza negativo. En este marco se interpreta que los principios de integración civil y política son lo bastante lábiles como para permitir que cada universo simbólico concurrente en la vida cotidiana pueda asumirlas en sus propios términos. Por encima de las idiosincrasias específicas, son los principios de la interacción y del intercambio comunicacional constante los que determinan una construcción y una autogestión discursiva de la realidad social, en que los «rasgos culturales» y los elementos de diferenciación no son, como se piensa, la fuente que determina los encuentros, las deliberaciones, las negociaciones y las luchas constantes, sino su resultado. No son diferen- cias sustantivas lo que provoca la diferenciación, sino que son las lógicas y dinámicas de clasificación diferenciadora lo que da como fruto las diferencias que clasifican. No nos diferenciamos porque somos diferentes: somos diferentes porque nos hemos o nos han diferenciado previamente.

\section{Por una ética situacional}

Una pedagogía que, frente a la retórica en última instancia vacía y larvadamente racista del multiculturalismo, hiciese el elogio de la civilidad, el civismo y la ciudadanía no podría pasar por alto que estos valores, por mucho que se instalen en la fundación misma del proyecto cultural de la modernidad, está muy lejos de haberse cumplido. La vida social y la actuación real de las instituciones aceptan sólo nominalmente los principios igualitarista y democráticos y por doquiern se hace patente cómo son la asimetría y las prácticas excluyentes lo que definen las parcelas más importantes de la vida colectiva. La asunción de unos principios mínimos de consenso, la prioridad concedida a lo que es justo, el acuerdo práctico entre formas de entender la vida distintas y hasta antagónicas..., todo eso permanece una pura posibilidad que dista todavía mucho de estructurar la vida civil. El ideal republicano es mucho más una meta, un horizonte, que una realidad realizada.

Ahora bien, esto no quiere decir que en la vida ordinaria no haya pruebas de que es posible esta forma de convivencia basada en la indiferencia ante las diferencias - que no ante las desigualdades, conviene matizar. A nuestro alrededor, en la experiencia diaria, tene- 
mos la oportunidad de contemplar cómo se constelan continuamente formas de convivencia basadas en la cooperación y la solidaridad automáticas entre personas que acuerdan coordinar sus acciones a partir de negociaciones en las que la «auténtica» identidad del otro es un dato irrelevante. Es verdad que las leyes no son todavía justas, que las exclusiones parecen el resultado inevitable de macroestructuras sociales inigualitarias y que demasiados seres humanos son juzgados $\mathrm{y}$ tratados en función de lo que son, o se supone que son y no de sus méritos y cualidades reales. Pero si de ello contamos con numerosos ejemplos, muchos más podríamos encontrar también de lo contrario, es decir de una convivencia simbiótica que se produce entre personas que a pesar de ser ostensiblemente diferentes, no ven convertida su diferencia en desigualdad.

Los lugares en que se demuestra masivamente que es posible e incluso inevitable la paz social entre distintos, hasta entre antagónicos, están bien cierca y cualquiera puede observarlos. Hablamos simplemente de las reuniones efímeras que tienen lugar en la calle, en los bares, en los vestíbulos de las estaciones, en el metro..., es decir en espacios públicos y semipúblicos en que -con todas las excepciones que se quiera- en general tiene lugar la autoorganización de una sociedad por definición justa, solidaria e igualitaria, a las antípodas de una estructura social y un orden político injustos, insolidarios y asimétricos. La vida cotidiana está ahí, simple y al mismo tiempo extraordinariamente intrincada, hecha de una inmensa multitud de trenzamientos los protagonistas de los cuales son desconocidos que ocultan o soslayan su verdad personal y que coordinan su actividad con otros de los que ni conocen ni les importa quiénes son en realidad.

En estos espacios públicos o semipúblicos, la circulación o la permanencia efímera de transeúntes puede ser considerada como una sucesión de arreglos de visibilidad y observabilidad ritualizadas, un constante ir y venir de iniciativas - no todas autorizadas ni pertinentes, por descontado-, en territorios ambiguos, cambiantes y sometidos a todo tipo de imbricaciones y yuxtaposiciones. El orden de la vida pública lo es de los acomodamientos sucesivos, una organización espacial de los tránsitos en que la liquidez y la buena circulación quedan aseguradas por una disuasión cooperativa, una multitud de micronegociaciones en que cada cual está obligado sólo a explicitar sus intenciones inmediatas, al margen de que proteja su imagen y respete el derecho de los demás a hacer lo propio. En estos casos, el distanciamiento y la dispersión garantizan un cierto nivelamiento entre personas cuya relación, en otros contextos plenamente estructurados y jerarquizados, aparecería determinada por todo tipo de exclusiones y asimetrías. En contextos públicos lo que se produce no es tanto una integración consecuente y voluntaria, sino los efectos de un colosal proceso automático de movilización, la función del cual es coordinar conductas y rectificar eventuales inconveniencias, actos fallidos, salidas de tono o «metidas de pata».

En estas circunstancias, es cierto que la copresencia de personas el status de las cuales son 
ostensible o potencialmente susceptibles de discriminación puede implicar malestar entre los protagonistas de la interacción. Pero este malestar se ha de superar en la medida que las reglas que rigen los agrupamientos sociales en espacios públicos parten del presupuesto de la igualdad en la accesibilidad. Ese espacio cognitivo que es la vida pública de los desconocidos obedece a pautas que van más allá -o bien que se sitúan antes, como se prefiera- de las lógicas institucionales y de las causalidades organicoestructurales, trascienden o se niegan a doblegarse a los requerimientos de las clasificaciones identitarias, puesto que aparecen autorregulándose en gran medida a partir de un repertorio de negociaciones y señales autónomos. Allí, en los espacios públicos y semipúblicos en que en principio nadie debería ejercer el derecho de admisión, dominan principios de reciprocidad simétrica, en los que lo que se intercambia puede ser perfectamente el distanciamiento, la indiferencia y la reserva, pero también el auxilio entre desconocidos en caso de emergencia. Para que todo ello sea posible es indispensable que los actores sociales pongan entre paréntesis sus universos simbólicos particulares y aplacen para mejor ocasión la proclamación de su verdad, todo en nombre de pautas minimalistas de cohabitación que suelen presentarse bajo el epígrafe general de la «buenas maneras» ${ }^{4}$, protocolos de deferencia y orden público que no por casualidad reciben el nombre de urbanidad.

Un enaltecimiento de todo ello lo sería también de aquella tradición que, a partir de los años cincuenta y sesenta, había desarrollado un conjunto de tendencias atentas especialmente a las situaciones, es decir, a las relaciones de tránsito entre desconocidos totales o relativos que tienen lugar preferentemente en espacios públicos. Tanto el interaccionismo simbólico como la etnometodología hicieron frente los modelos del funcionalismo macrosociológico, postulando paradigmas epistemológicos alternativos, más atentos a coyunturas limitadas y redefinibles que a las estructuas, y más a los procesos concretos de interacción humana que la «auténtica» identidad de sus protagonistas. Sus trabajos versaban sobre todo comportamientos significativos en situación, en los que los intervinientes que se sumergen en cada secuencia de acción usaban conocimientos y técnicas con frecuencia adquiridos espontáneamente durante interacciones anteriores. La situación es una sociedad en sí misma, dotada de leyes estructurales inmanentes, autocentrada, autoorganizada al margen de cualquier contexto que no sea el que ella misma genera. Dicho de otra manera, la situación es un fenómeno social autorreferencial, en que es posible reconocer dinámicas autónomas de concentración, dispersión, conflicto, conseso y recomposición, y en que las variables espaciales y el tiempo ejercen un papel fundamental, precisamente por la tendencia a la improvisación y a la variabilidad que experimentan unos componentes obligados a renegociar constantemente su articulación ${ }^{5}$. Los valores de radicalismo democrático de la situación fueron trasladados por los situacionistas franceses de los años 50 y 60 al campo de la creación artística y urbanística, como también al del activismo político revolucionario. Para ellos, la situación construida 
consistía en un «momento de la vida construido de una manera concreta y deliberada por medio de la organización colectiva de un ambiente unitario y un juego de acontecimientos ${ }^{6}$. Para el análisis de las situaciones, la personalidad identitaria de los actores sociales -tanto en el ámbito psicológico individual como a nivel de su adscripción a una cultura determinada- no era el punto de patida de las explicaciones, a través del cual se acababa llegando al esclarecimiento de la conducta concreta, sino al revés. Era a partir del comportamiento concreto que se podía llegar a una idiosincrasia individual o cultural que era su producto, una construcción interesada hecha a posteriori y con funciones racionalizadoras. En cada contexto autodeterminado, es decir, en cada secuencia, los actores movilizan recursos previos, ya sean psicológicos y culturales, pero lo hacen adaptándolos a las emergencias a que por fuerza se han de ir adaptando, improvisando, por medio de una red de acuerdos sobre la marcha, regiones de significación siempre inéditas e inopinadas.

Cabría evocar aquí las aportaciones que promuevan respeto a esto la sociolinguística interaccional a propósito de los acuerdos linguiísticos que se reproducían constantemente en las sociedades urbanizadas, definidas precisamente por su condición heterogénea. El punto de partida es el valor competencia adoptado de la lingüística generativa. Para Chomsky la competencia es la capacidad virtual de producir y comprender un número infinito de enunciados, como también de manipular una cantidad no menos indeterminada de códigos. Se trata de un saber, una facultad o potencialidad latente previa a la acción y requisito para ella. De aquí parten autores como Dell Hymes a la hora de proponer el concepto de competencia de comunicación ${ }^{7}$, alusivo a la facultad explícita o implícita, simétrica o desigual, que permite a un sujeto cualquiera conocer las normas psicológicas, sociales o culturales que están presupuestas en todo acto de comunicación, ya sea éste contractual o polémico.

La sociolingüística interaccional basa sus postulados en tres nociones esenciales: la conmutación de código, competencia social básica que ejercen actores extraídos de grupos culturales, de clase, de edad o lingüísticos completamente distintos, que participan en unos mismos encuentros y que se ven obligados a poner en común su competencia comunicativa; los índices de contextualización, que son los recursos que reclaman o producen los inteactuantes para definir las situaciones en que participan y establecer las estrategias y los consensos provisionales que permiten moverse adecuadamente, y la inferencia comunicacional, o lógica práctica para aquella puesta en congruencia de la que depende la mutua inteligibilidad de los interactuantes y la negociación y los compromisos entre ellos. La idea de competencia comunicativa remite a la estructuración de los intercambios linguiísticos entendidos como organización de la diversidad, en marcos sociales -la vida urbana cotidiana, sin ir más lejos- en que todos dependemos o en cualquier momentos podemos depender de personas - a veces desconocidos totales- con las que es posible que compartamos pocos o ningún rasgo cultural. El lenguaje no expresa entonces una comuni- 
dad humana, como había querido la linguiística derivada del romanticismo o, más tarde, el relativismo lingüístico y cultural, sino una acción que se desarrolla con fines prácticos de cooperación entre individuos que han de compartir un mismo escenario y que participan de unos ismos acontecimientos. Cada momento social concreto implica una tarea inmediata de socialización de los copartícipes, una tarea en que los actores aprenden rápidamente cuál es la conducta adecuada, cómo manejar las impresiones ajenas y cuáles son las expectativas suscitadas. Existen -es cierto- sistemas lingüísticos y culturales subyacentes, pero son estos los que resultan determinados por su uso por parte de los hablantes y no al revés, como supondría el idealismo lingüístico o las escuelas cultualistas en antropología.

Un enfoque de este tipo resulta idóneo para circunstancias sociales en que el colectivo de hablantes-oyentes no es culturalmente homogéneo y sus componentes circunstanciales han de plegarse una y otra vez a contingencias contextuales fundadas en la pluralidad de tradiciones, códigos y biografías personales, que obligan a ajustes y reajustes ininterrumpidos que, a su vez, generan morfologías sociales y universos cultuales compartidos durante un breve lapso de tiempo. Estas circunstancias de encuentro y colaboración entre distintos culturales, en las que los malentendidos y las interferencias suelen ser frecuentes, pueden, a pesar de ello $\rightarrow$ acaso por ello-, generar sentimientos de simpatía e incluso de adhesión, la base de los cuales no es el particularismo cultual sino aquello que el lenguaje cultivado hace tiempo que viene llamando cosmopolitismo.
El espacio público es la esfera de copresencia en que este tipo de interrelaciones entre desconocidos totales o relativos que quieren continuar siéndolo, un escenario en que la conviencia entre extraños, quién sabe si potencialmente ncompatibles en otros planos de la vida social, se demuestra viable, a partir de una serie de mínimos competenciales consensuados con frecuencia sobre la marcha. Las puestas en común no están basadas aquí en una comunión, sino en la comunicación. Los presentes no comulgan, sino que negocian y renegocian constantemente los términos de su vinculación. Lo que se articula no son autenticidades identitarias, sino roles en los que la impostura y la mentira no están nunca del todo descartadas. Lo que entra en juego entonces no son las verdades personales de cada cual, sino exterioridades, apariencias que dan a escoger entre todas las gamas del trecho que va de una interacción focalizada a otra basada en la indiferencia. No es una intersubjetividad, como se pretendería desde perspectivas fenomenológicas, sino una pura interobjetividad, el pacto abierto que firman personas que quieren ser tomadas no por lo que son o creen ser, sino tan sólo por lo que parecen o pretenden parecer. Reducido a una organicidad mínima, este escenario es cualquier cosa menos el de una comunidad territorializable. Ahí lo que se da es una solidaridad automática entre personas que autogestionan sus formas de cooperación, que se interpelan unas a otras usando todo tipo de sobreentendidos y dobles lenguajes $y$ que incluso pueden convivir mediante la paradójica vía de ignorarse mutuamente. 


\section{Democracia contra comunidad}

Se cumple de este modo ese principio teórico que opone de forma irrevocable el espacio público al territorio común. Los principios de visibilidad y publicidad que deben regir por principio la vida pública democrática se hallan en los antípodas de los que organizan cualquier modalidad de comunidad. La comunidad como entidad mística que traslada a la vida social el principio de la consubstancialización divina del cristianismo ${ }^{8}$. Esa conjunción se produce bajo la forma de una corporeización de la sociedad, pero una corporeización orgánica de la que la proyección menor sería el hogar y la mayor la patria. En cualquiera de sus formalizaciones, el concepto moderno de comunidad -incluso cuando es empleado por las ciencias sociales- no puede esconder sus fuentes puramente teológicas, derivadas a su vez en el mito de una convivencia que se considera real fuera o antes de la vida urbana en las sociedades modernas y que supuestamente se basaba en el consenso, la franqueza y el respeto al pasado, una forma de sociedad en que cada lugar estructural era consecuente con todos los demás, en la que lo imprevisto era raro y podía ser rápidamente neutralizado. Es decir, un modelo de sociedad establecido en términos de coherencia, concretado en congregaciones unidas por vínculos hechos de calor y verdad, claramente enclavadas en un territorio que consideraban propio, relativamente pequeñas, compartiendo valores y visiones del mundo, más bien autárquicas, provistas de un poderoso sentido de la pertenencia identitaria y en las que dominaba lo sagrado. Ese tipo de sociedades eran las mismas -no se olvide- cuya existencia la antropología había recibido en cierto modo la misión de certificar como existiendo todavía en algún sitio, dando testimonio de una posibilidad permanentemente desperdiciada de vivir «de otro modo». Sociedades estructuradas, integradas, consecuentes... Nada que ver con la confusión, la dislocación, la dependencia respecto de la economía monetaria, la identidad estallada y la secularización que convertían las ciudades en un lugar para el pecado y la desesperación. Esta idea no puede ser desvinculada del referente que le presta la imagen de la comunidad cristiana, tal y como se concreta ya sea a través de la Iglesia católica o de las diferentes expresiones del sectarismo protestante. A una sociedad homogénea, religiosa, familiar y personalizada, que fuera general en otros sitios y en otras épocas y que ahora malsobrevive en un mundo sin alma, se le opone lo que es la sociedad contemporánea, en que lo que prima es una sociedad heterogénea, secular, individualizada y despersonalizada. Por mucho que las ciencias sociales le aplicara distintas descripciones -solidaridad mecánica/solidaridad orgánica, Gemeinschaft/Gesellschaft, sociedad folk/sociedad urbana...-, esa oposición es siempre la que opone una sociedad preocupada hasta la obsesión por la coherencia a otra que se conforma con articular modos minimalistas de convivencia y que aspira ante todo a la cohesión. Si la primera se organiza a partir de la comunión permanentemente renovada de sus miembros, la segunda tiene como requisito el que éstos basen su relación en la práctica no menos ininterrum- 
pida del intercambio y el acuerdo, es decir en la comunicación.

Hannah Arendt, cuya teoría sobre el espacio público no debería dejar nunca de merecer nuestro elogio, vio la esfera pública como aquella en que prima la visibilidad, el nexo entre las personas se basa en su apariencia y se espera de las conductas que sean ante todo apropiadas. A años luz de ese diseño de lo público, y sin duda contra él, todo fundamentalismo se funda en la exigencia de formar un corpus, un órgano de vida social cuyos miembros estuvieran vinculados entre sí como si fueran miembros de una familia y aceptaran someterse a una única visión del mundo que garantizase la congruencia básica del grupo. Incompatible con ese principio de comunión, «la realidad de la esfera pública radica en la simultánea presencia de innumerables perspectivas y aspectos en los que se presenta el mundo común y para el que no cabe inventar medida o denominador común... Ser visto y oído por otros deriva su significado de que todos ven y oyen desde una posición diferente». Lo que sostiene Arendt es que, aunque pueda parecer una contradicción, la posibilidad misma de un mundo común no puede asentarse en la naturaleza común de los seres humanos que lo conforman, sino «por el hecho de que, a pesar de las diferencias de posición y la resultante variedad de perspectivas, todos están interesados en el mismo objeto ${ }^{9}$. Nada más alejado de la cohesión automática que rige en un espacio público sin verdad, que la coherencia cultural que reclama y proclama despóticamente cualquier forma de fusión comunitaria, que acabará basando su búsqueda frenética de autenticidad en la exclusión de todo cuanto se le antoje un peligro o un estorbo. Territorio público es, decidamente, un imposible lógico, una pura antinomia.

Es cierto que los discursos de la ciudadanía y de la democracia están determinados -en cierto modo ensuciados- por el pecado original de haber nacido de y al servicio de una determinada concepción del mundo que no puede considerarse en absoluto inocente. Ahora bien, acaso la astucia de los partidarios de la justicia y la igualdad humana deberían aprender que la historia no ha consistido sino en las distintas maneras como un conjunto de reglas han sido usadas - sin dejar de ser nunca las mismas- en sentidos distintos e incluso inversos. Será posible, en ese orden de cosas, que, como pensaba Michel Foucault, «la violencia haga violencia a la violencia, y que otra dominación pueda doblegar a los mismos que dominan». Interpretar las reglas del juego, en efecto, puede ser apropiarse de ellas, usufructuarlas o confiscarlas en beneficio de otros distintos de quienes las generaron, someterlos a principios de acción inesperados e imprevisibles. Escribía Foucault: «El gran juego de la historia es para quien se apodere de ellas [de las reglas], ocupe el puesto de los que las utilizan, se disfrace para pervertirlas, utilizarlas al revés y volverlas contra los que las habían impuesto; para quien introduciéndose en el complejo aparato lo haga funcionar de tal forma que los dominadores se encuentren dominados por sus propias reglas ${ }^{10}$.

Puede afirmarse, sin temor a error, que los grandes combates civiles en pos de la igual- 
dad van a desarrollarse -se están desarrollando ya- en y por el espacio público. En ese proscenio -del que la calle es la máxima expresión física- se producen las presiones del orden económico dominante para convertir al ciudadano en un consumidor sumiso. A esa labor de clientelización del ciudadano contribuye una máquina de centralización política -el Estado-, que se niega a replegarse a lo que se supone es su sentido último, que es el de servir a sus administrados. Para ello, sofistica cada vez más sus estrategias de fiscalización y trata de perpetuar su actual papel al tiempo represivo y parasitario. De ese destino como lugar para la vigilancia y la rentabilidad el espacio público es rescatado por luchas sociales, que entienden que el conflicto es la máxima y más eficaz arma de cohesión social. Porque en ella se reagrupan todas las formas de insumisión, la calle es el escenario en que se da a contemplar, agitándose periódicamente, lo inamistoso de las ciudades.

\section{NOTAS}

Véase, por ejemplo, J. Ch. Müller y M. Tuckfeld, «Dos racismos con futuro: sociedad civil y multiculturalismo», en VV. AA., Extraños en el paraiso, Virus, Barcelona, 1994, pp. 273-292.

${ }^{2}$ «... La desigualdad de crédito y de autoridad se vuelve inevitable entre los individuos tan pronto como, reunidos

pararse entre sí y tener en cuenta las diferencias que encuentran en el uso constante que han de hacer los unos de los otros» (J. J. Rousseau, Discurso sobre el origen y los fundamentos de la desigualdad entre los hombres, Península, Barcelona, 1976, p. 98).

3 J. Habermas, Facticidad y validez, Trotta, Bilbao, 1998. Una formalización resumida de la polémica entre el republicanismo identitario de Tylor y el republicanismo kantiano de Habermas, en C. Thiebaut, «Democracia y diferencia: un aspecto del debate sobre el multiculturalsmo», Anales de la Cátedra Francisco Suárez, Granada, 31 (1994), pp. 43-60. Sobre las limitaciones del modelo habermasiano ante las realidades del mundo capitalista, J.-M. Vicent, «Théorie critique et républicanisme kantien», Futur Antérieur, 41'42 (1998), 201-223.

4 Cf. I. Joseph, «Buenas maneras», en Erving Goffman y la microsociología, Paidós, Barcelona, 1999, pp. 17-34.

${ }^{5}$ Cf. M. Agier, «Moments partagés: la ville relationnelle», en L'ínvention de la ville. Banlieus, towships, invasionset favelas, Éditions des Archives Contemporaines, París, 1999.

"Del artículo «Définitions», aparecido sin firma en el primer número de International Situacioniste, en 1958. Reproducido en L. Andreotti y X. Costa, Teoría de la deriva $i$ altres textos situacionistes sobre la ciutat, MACBA, Barcelona, 1997, p. 68.

${ }^{7}$ Cf. D. H. Hymes, Vers la compétence de communication, Hatier/Didier, París, 1992.

${ }^{8}$ Cf. E. Tassin, «Espace comun ou espace public? L'antagonisme de la communauté et de la publicité», Hermes, 10 (1991), pp. 23-37.

${ }^{9}$ H. Arendt, La condición humana, Paidós, Barcelona, 1998, pp. 66-67.

${ }^{10}$ M. Foucault, Nietzsche, la genealogía, la moral, Pretextos, Valencia, 1992, pp. 40-41. 